\title{
A Prospective Examination of Patterns and Correlates of Exercise Maintenance in Coronary Artery Disease Patients
}

\author{
Yvonne W. Leung $\cdot$ Natalie Ceccato $\cdot$ Donna E. Stewart $\cdot$ \\ Sherry L. Grace
}

\begin{abstract}
This longitudinal study examined exercise behavior patterns (i.e., maintainers, irregular, and inactive) in cardiac patients, and investigated the sociodemographic, clinical, psychosocial; and environmental correlates of exercise patterns. A total of 661 cardiac in-patients from three hospitals consented to participate (75\% response rate) and were re-assessed 9 and 18 ( $81 \%$ retention) months post-discharge. Exercise patterns were assessed via the Health-Promoting Lifestyle Profile II subscale using a median split. Of 417 participants (mean age $63.1 \pm 10.2$ ) with complete data, $42.2 \%$ were classified as Exercise Maintainers, $21.3 \%$ as Irregular Exercisers, and $26.1 \%$ as Inactive. Multinomial logistic regression revealed that Exercise Maintainers were more likely to be male, have exercised prior to their diagnosis, attend cardiac rehabilitation, perceive fewer exercise barriers, and were less likely to be current-smokers, past-smokers, or attribute the cause of their disease to their own behavior. Patients more likely to maintain exercise have positive perceptions and utilize cardiac rehabilitation.
\end{abstract}

Keywords Exercise maintenance - Physical activity Cardiac rehabilitation - Irregular exercisers . Inactivity and acute coronary syndrome

Y. W. Leung (凶) . S. L. Grace

Kinesiology and Health Science, 222A Bethune College,

York University, 4700 Keele Street, Toronto,

ON M3J1P3, Canada

e-mail: yleung@yorku.ca

N. Ceccato - D. E. Stewart - S. L. Grace

University of Toronto, Toronto, ON, Canada

D. E. Stewart - S. L. Grace

University Health Network, Toronto, ON, Canada

\section{Introduction}

Coronary artery disease (CAD) is the leading cause of mortality and morbidity in Canada (Manuel et al. 2006). The impact of exercise on cardiac therapeutic and preventive outcomes including reduced rates of cardiac events, morbidity, and mortality is well established (Gielen and Hambrecht 2001; Jassen and Jolliffe 2006; Leon et al. 2005). Research not only indicates exercise has the ability to prevent, slow progression, and reverse risk indicators among populations with $\mathrm{CAD}$ (Chan et al. 2006b; Hambrecht et al. 1993; Niebauer et al. 1997), but might also have a protective effect, mitigating the impact of other existing risk factors (Blair et al. 1996). While this is encouraging given exercise behavior is modifiable, it is also problematic given the complexity of initiating and maintaining exercise behavior change (Roitman and LaFontaine 2001). This is clearly evident when examining exercise behavior in both general and cardiac populations (Reid et al. 2006). For instance, Reid et al. (2006) examined exercise behavior among cardiac patients over 12 months post-discharge. They showed that while cardiac patients increased their exercise immediately postdischarge, they did not maintain this increased exercise level beyond 2 months post-discharge.

Research examining physical activity correlates in non-medical adult populations has included a broad range of factors including sociodemographic (e.g., age, sex), psychosocial (e.g., support, barriers), and environmental (e.g., cold weather) variables (Chan et al. 2006a; O'Clark 1999; Wilcox and Storandt 1996). However, while research has explored our understanding of exercise patterns in cardiac rehabilitation, there is a lack of longitudinal studies examining multi-level exercise correlates in a broader sample of cardiac patients, particularly 
with a focus on exercise maintenance. This is critical given that only $15-20 \%$ of cardiac patients would be represented in studies of cardiac rehabilitation (Grace et al. 2002). The objectives of this study were to: (1) longitudinally examine exercise patterns (maintenance vs. irregular vs. inactive) among cardiac patients for 18 months after hospitalization, and (2) identify sociodemographic (e.g., age, sex, marital status, family income, education), clinical (e.g., functional capacity, exercise history, body mass index, diabetes, smoking), psychosocial (i.e., exercise barriers and benefits, anxiety and depression symptoms, illness perceptions, social support) and environmental (i.e., season) correlates of these exercise patterns.

\section{Methods}

Participants

This research constitutes secondary analyses from a study regarding cardiac rehabilitation referral (Grace et al. 2007b). Cardiac in-patients were recruited from the Toronto General and Western Hospitals and Trillium Health Centre in Ontario, Canada. Inclusion criteria were diagnosis of confirmed myocardial infarction, unstable angina, or congestive heart failure based on medical chart reviews, including in-patients for percutaneous coronary interventions (PCI) or acute coronary bypass procedures. Exclusion criteria from the larger study were medical instability, ineligibility for or previous participation in cardiac rehabilitation, lack of English language proficiency, or being under the age of 18 .

Of 1,362 patients approached between September 2003 and August 2004, 661 consented, 218 declined, and 483 were ineligible (75\% response rate). Reasons for ineligibility were as follows: previous attendance at cardiac rehabilitation $(n=123 ; 25.5 \%)$, lack of English language proficiency $(n=119 ; 24.6 \%)$, too ill to participate $(n=98$, $20.3 \%)$, condition not indicated for referral to cardiac rehabilitation $(n=70 ; 14.5 \%)$, patient too confused or experiencing cognitive impairment $(n=42 ; 8.7 \%)$, comorbid musculoskeletal condition which precludes ambulation $(n=19 ; 3.9 \%)$, or patient already participating in two studies $(n=5,1.0 \%)$. Other reasons $(n=7,1.4 \%)$ included isolation for infection control and moving to another province. Characteristics of participants and nonparticipants revealed no difference in marital status or site of recruitment. However, there were other significant sociodemographic differences between the participants and non-participants which are fully outlined in a previous paper (Grace et al. in press).
Procedure

This study was approved by the University Health Network, Trillium and York University Research Ethics Boards. Upon consent, participating in-patients were provided a questionnaire assessing sociodemographic characteristics, exercise behavior, and psychosocial correlates. Clinical data were extracted from patient charts. Nine and 18 months post-discharge exercise behavior was again assessed via mailed questionnaires. Dillman's tailored design method (Dillman 2000) was used to optimize response rate. Within all questionnaires, participants were asked to enter the date they were completing the survey.

\section{Measures}

\section{Dependent Variable}

The exercise behavior subscale of the Health Promoting Lifestyle Profile (HPLP II; Walker et al. 1987) was administrated in hospital, and 9 and 18 months postdischarge to assess patient's participation in recreational and physical activities over time. The in-hospital assessment asked participants to report on their exercise behavior before their cardiac hospitalization. The subscale consists of eight items rated on a 4-point Likert scale $(1=$ never, $2=$ sometimes, $3=$ often $4=$ routinely). A mean score was computed, with possible scores ranging from 1 to 4 and higher scores indicating greater exercise participation. The Cronbach's alpha reliability coefficient of HPLP II exercise subscale was 0.85 in the current sample in hospital, 0.88 at 9 months, and 0.87 at 18 months postdischarge.

A median split was used to classify participants as exercisers or non-exercisers at each time point. A score equal or greater than the median was used to classify the participant as an exerciser for that time period. A median split was used to ensure that operationalization of exercise was relative to the broad cohort, and there would be an equal sample size in each group. Then participants were classified into one of the following three groups: (1) Exercise Maintainers or patients who were categorized as exercisers in-hospital and 9 and 18 months post-discharge, or at 9 and 18 months postdischarge only; (2) Inactive or patients who were categorized as a non-exerciser at all three time points; and (3) Irregular Exercisers or patients who exercised in any time period but did not maintain their exercise behavior across two consecutive time points (see Table 1). Other exercise constellations were excluded from further analyses. 
Tahle 1 Exercise categorization based on self-reported exercise in-hospital and 9 and 18 months post-discharge

\begin{tabular}{|c|c|c|c|c|c|}
\hline & $\begin{array}{l}\text { In-Hospital } \\
N=649\end{array}$ & $\begin{array}{l}9 \text { months Post-discharge } \\
n=513\end{array}$ & $\begin{array}{l}18 \text { months Post-discharge } \\
n=445\end{array}$ & $n$ & $\%$ \\
\hline \multirow[t]{2}{*}{ Exercise Maintainers } & $\mathrm{x}$ & $\mathrm{x}$ & $\mathbf{x}$ & 130 & 31.2 \\
\hline & 0 & $\mathrm{x}$ & $\mathrm{x}$ & 46 & 11.0 \\
\hline Total no. of Exercise Maintainers & & & & 176 & 42.2 \\
\hline \multirow[t]{3}{*}{ Irregular Exercisers } & 0 & $\mathrm{x}$ & 0 & 22 & 5.3 \\
\hline & $\mathbf{x}$ & $\mathbf{x}$ & 0 & 26 & 6.2 \\
\hline & $\mathbf{x}$ & 0 & 0 & 41 & 9.8 \\
\hline Total no. of Irregular Exercisers & & & & 89 & 21.3 \\
\hline Inactive Patients & 0 & 0 & 0 & 109 & 26.1 \\
\hline Total no. of Inactive Patients & & & & 109 & 26.1 \\
\hline \multirow[t]{2}{*}{ Excluded } & 0 & 0 & $x$ & 16 & 3.8 \\
\hline & $\mathrm{x}$ & 0 & $\mathbf{x}$ & 27 & 6.5 \\
\hline Total no. of Excluded & & & & (43) & 10.3 \\
\hline Total no. of Exercisers $(n /(\%))$ & $327(50.4 \%)$ & $258(50.3 \%)$ & $232(52.1 \%)$ & 374 & 100 \\
\hline
\end{tabular}

Exercisers (HPLP II Exercise score $\geq$ median ) $=x$

Non-Exercisers (HPLP II Exercise score $<$ median ) $=0$

\section{Sociodemographic Correlates}

Self-reported sociodemographic data assessed in the baseline questionnaire included ethnocultural background, marital status, work status, and gross family income through forced-choice options. Age and sex were recorded from patient charts.

\section{Clinical Correlates}

The type of cardiac diagnoses or procedures for which the patient was admitted was recorded from patient charts. A dichotomous variable was created to indicate whether the patient was admitted for PCI, given this was the most frequent condition or procedure (i.e., PCI vs. all other diagnoses or procedures). Clinical data including smoking status and presence of selected comorbid conditions (e.g. diabetes, hyperlipidemia) were also extracted from patients' medical charts.

To determine obesity status, body mass index (BMI) was computed based on self-reported height and weight $\left(\mathrm{kg} / \mathrm{m}^{2}\right)$. If the BMI was greater than 30 , the patient was classified as obese (World Health Organization 2006). Exercise history was determined by one item (yes/no) which asked "Did you exercise to the point of getting short of breath on a regular basis (as an adult) prior to your cardiac event?" Participants were also asked to report whether they enrolled in cardiac rehabilitation (yes/no) in the 9 month survey.

To assess functional capacity, the Duke Activity Status Index (Hlatky et al. 1989), a brief 12-item self-report instrument was administered. Participants were asked about their ability to perform common activities of daily living, such as personal care, ambulation, household tasks, sexual function, and recreational activities, which are each associated with specific metabolic equivalents (METs). This valid and common tool correlates highly with peak oxygen uptake (Nelson et al. 1991). The Cronbach's alpha reliability coefficient was 0.88 in the current sample.

\section{Psychosocial Correlates}

The Exercise Benefits and Barriers Scale (Sechrist et al. 1987) was administered in the in-hospital survey package to assess patients' exercise perceptions. This is a 43 -item scale, where items are assessed on a 4-point Likert scale. In the current study the Barriers subscale was used, which consists of 14 items and assesses a person's belief about negative aspects of routine exercise. Higher scores on the subscale indicate more perceived barriers. Cronbach's alpha reliability coefficient was 0.85 for the barriers scale in the current sample.

The Hospital Anxiety and Depression Scale (Zigmond and Snaith 1983), a reliable and well-validated scale (Bjelland et al. 2002), was used to assess anxiety and depressive symptoms. This is a 14-item self-report questionnaire. Anxiety and depressive symptomatology were each measured through seven items rated on a 4-point Likert-type scale. Total scores range from 0 to 21 , where a score below 8 indicates the 'normal' range of subthreshold symptoms, a score of 9-10 represents moderate symptomatology, and a score of 11 or greater represents severe symptomatology (Zigmond and Snaith 1983). The Cronbach's alpha reliability coefficient of the anxiety subscale 
was 0.82 for the in-hospital assessment and 0.86 at 18 months post-discharge, and, 0.78 and 0.83 respectively for the depression subscale.

The Revised Illness Perception Questionnaire (MossMorris et al. 2002) was used to assess patients' cognitive representations of their cardiac condition. The subscales of timeline, cyclical or episodic, consequences, personal control and curability/controllability were incorporated, and were measured using four to six items each on a 5point Likert scale. Higher scores on each subscale indicate a strong belief that the illness is chronic, symptoms are cyclical, greater perceived consequences of illness, lower control of illness, and an inability to control or cure the illness, which were indicative of a negative perception of the illness, respectively. Cronbach's alpha reliability coefficients for each of the subscales ranged from 0.80 for personal control dimension to 0.91 for the timeline cyclical dimension in the current sample. The cause subscale of the Revised Illness Perception Questionnaire was also administered in-hospital assessment, and the item "my own behavior" attributed as a cause of their cardiac condition was included as a correlate in this study. Here, participants were asked to rate the cause on a 5-point Likert scale ranging from 'strongly disagree' to 'strongly agree'.

The Medical Outcomes Study Social Support Survey (Sherbourne and Stewart 1991) was used to measure participants' levels of perceived social support in hospital. The instrument is self-administered through a 5-point Likert-type response scale from 1 "none of the time" to 5 "all of the time." The survey has four subscales, namely tangible support, emotional support, affectionate support, and positive social interactions. An additional item covers the structural (size of social network) aspect of support. Scores are calculated for each of the subscales, and a total social support score is also computed. The Cronbach's alpha values for tangible support was $0.86,0.81$ for emotional support, 0.88 for affectionate support, and 0.93 for positive social interactions in the current sample.

\section{Environmental Correlate}

Season was considered to control for effects of cold weather and icy conditions which may make exercise behavior more difficult. A dichotomous variable was created for each assessment time point to indicate whether the survey was completed in December, January, or February, versus a non-winter month. Overall, 358 (28.2\%) participants completed the in-hospital assessment during the winter months, $146(28.5 \%)$ at 9 months post-discharge, and $101(22.6 \%)$ at 18 months post-discharge.

\section{Statistical Analyses}

Data were cleaned and screened. As an additional check on the validity of our exercise measure, Pearson's correlation was used to relate HPLP II Exercise scores to the Borg Rating Scale of Perceived Exertion (Borg 1974) administered 18 months post-discharge. The variables were significantly correlated $(r=0.449, p<0.001)$, lending credence to the validity of our exercise measure.

A descriptive analysis of exercise patterns was conducted. Change in exercise scores were tested using repeatedmeasures ANOVA. Bivariate screening using Pearson's Chisquare and ANOVA as appropriate was conducted to test for significant differences in the correlate variables by exercise pattern. The significant correlates were entered into the logistic regression model. Multinomial logistic regression was used to compare the three exercise groups simultaneously: Exercisers Maintainers versus Inactive participants and Irregular Exercisers versus Inactive participants. Finally, a logistic regression model was used to identify significant correlates of Irregular Exercisers when compared to Exercise Maintainers. The criterion for entry was $p<0.05$. All analyses were performed using SPSS version 14.

\section{Results}

\section{Respondent Characteristics}

Of the 661 consenting participants, 61 were ineligible and 506 were retained 9 months post-discharge (retention rate $=506 / 600=84.3 \%$ ). Reasons for ineligibility were as follows: unable to reach/incorrect contact information $(n=34 ; 5.1 \%)$, too ill to participate $(n=10 ; 1.5 \%)$, deceased $(n=8 ; 1.2 \%)$, and other reasons $(n=9 ; 1.4 \%)$.

At 18 months post-discharge, 465 participants were retained in the study. Characteristics of participants and those who declined or were ineligible at 18 months postdischarge were described in a previous publication (Grace et al, in press). The retention rate was $81.4 \%$. Reasons for ineligibility were as follows: cannot reach/incorrect contact information ( $n=55 ; 61.1 \%$ ), too ill to take part ( $n=13$; $14.4 \%)$, deceased $(n=10 ; 11.1 \%)$, previous participation in cardiac rehabilitation $(n=3 ; 3.3 \%)$, and other reasons $(n=9 ; 10 \%)$ included onset of conditions which precluded eligibility for cardiac rehabilitation.

There were significant differences in exercise scores between retained and non-retained participants. Those retained in the study 9 months post-discharge had significantly higher in-hospital HPLP II exercise scores than those lost to follow-up $(t=-2.86, p<0.005)$. Similarly, those retained in the study 18 months post-discharge had 
significantly greater 9 month exercise scores than those lost to follow-up $(t=-3.28, p<0.001)$. This implies that participants who had higher exercise scores were more likely to remain in the study.

\section{Exercise Behavior}

The mean HPLP II exercise subscale scores were 1.75 (standard deviation $[\mathrm{SD}]=0.72 ;$ median $=1.90$ ) in hospital, $2.36(\mathrm{SD}=0.80$; median $=2.38$ ) at 9 months, and 2.25 $(\mathrm{SD}=0.77 ;$ median $=2.25)$ at 18 months post-discharge . Repeated measures ANOVA with Bonferroni post-hoc tests were used to assess change in HPLP II exercise scores across the three time points $(F=89.85, p<0.001)$. Post-hoc tests showed that in-hospital exercise behavior was significantly lower than it was at 9 months post-discharge $(p<0.001)$ and 18 months. Exercise behavior at 9 months was significantly higher than at 18 months post-discharge $(p<0.001)$, but still significantly higher than in-hospital exercise behavior $(p<0.001)$.

Table 1 displays the frequency of exercise patterns based on median split. The exercise pattern of 43 participants did not match our criteria, and were excluded from further analyses.

\section{Correlates of Exercise Patterns}

Table 2 displays the sociodemographic, clinical, and psychosocial/ behavioral correlates of interest by exercise pattern. As shown, in bivariate analyses the following correlates differentiated between Exercise Maintainers, Irregular Exercisers and Inactive participants: sex, family income, functional status, cardiac rehabilitation participation, diabetes, obesity, smoking, exercise barriers, perception of illness timeline, and attribution illness to one's own behavior. To optimize power and prevent multicollinearity, only significant variables at the bivariate level were entered into the multinomial logistic regression and logistic regression model.

The multinomial logistic regression model (Table 3) showed that compared to Inactive participants, Exercise Maintainers were significantly more likely to be male, to have an exercise history, to be a cardiac rehabilitation enrollee, less likely to perceive exercise barriers, to attribute the cause of CAD to their own behavior, and to be current or past-smoker. Compared to Inactive participants, Irregular Exercisers were more likely to be a cardiac rehabilitation enrollee, and less likely to perceive exercise barriers. The overall model was significant $\left(\chi^{2}=111.608\right.$, $p<0.0001$ ).

Table 4 shows a logistic regression model comparing Exercise Maintainers to Irregular Exercisers. Irregular
Exercisers were more likely to be current smokers, diabetic, and to attribute CAD to their own behavior. The overall model was significant $\left(\chi^{2}=30.916 ; p<.005\right)$.

\section{Discussion}

While a plethora of research has examined the correlates of exercise in healthy populations (Trost et al. 2002), few have examined the correlates of exercise in general cardiac populations (Grace et al. 2007a; Reid et al. 2006), and none to our knowledge have investigated the correlates of exercise maintenance. Research suggested this as a fruitful avenue for future research (Brawley et al. 2003), considering that an understanding of modifiable characteristics related to activity may enable sustained activity and ultimately have favorable effects on cardiac secondary prevention. The objective of the current study was to examine exercise patterns in cardiac patients including correlates of sustained and irregular exercise behavior. Significant correlates associated with exercise maintenance included male gender, attending cardiac rehabilitation, prior exercise history, being a non-smoker, perceiving lower exercise barriers, and being less likely to attribute their disease to their own behavior.

Overall, almost half of participants were classified as Exercise Maintainers, over one-quarter as Inactive, and one-fifth as Irregular Exercisers. The high rate of exercise maintainers in this study is a function of our use of a median split for exercise categorization, and is clearly higher than rates of exercise among cardiac patients reported elsewhere (Reid et al. 2006). Although these findings may also represent inaccurate reporting or recall bias due to the nature of self-report measurement, they do however suggest that up to half of cardiac patients are attempting to incorporate physical activity into their lifestyle up to a year and a half following a cardiac event or procedure.

The high number of Irregular Exercisers found is also telling. This suggests that many cardiac patients are making concerted efforts to incorporate exercise into their life, but are experiencing barriers to successful maintenance. This group of exercisers is ripe for identification to ensure the implementation of evidence-based interventions. This is also supported by the finding that participants' overall exercise behavior increased at 9 months post-discharge however, dropped slightly by 18 months. This may indicate participants had greater motivation to increase their exercise levels after hospital discharge, but they find it difficult to maintain their exercise behavior over time. Identifying facilitators and addressing barriers is invaluable to promoting sustained exercise in this population. 
Table 2 Correlates of exercise behavior patterns

\begin{tabular}{|c|c|c|c|c|c|c|c|c|c|c|c|}
\hline \multirow[t]{2}{*}{ Type } & \multirow[t]{2}{*}{ Correlate } & \multicolumn{2}{|l|}{$\begin{array}{l}\text { Inactive } \\
n=109\end{array}$} & \multicolumn{2}{|c|}{$\begin{array}{l}\text { Exercise } \\
\text { Maintainers } \\
n=179\end{array}$} & \multicolumn{2}{|c|}{$\begin{array}{l}\text { Irregular } \\
\text { Exercisers } n=89\end{array}$} & \multicolumn{2}{|c|}{ Total $N=374$} & \multirow[t]{2}{*}{$F$-test $/ \chi^{2}$} & \multirow[t]{2}{*}{ Sig } \\
\hline & & Mean $/ n$ & $\mathrm{SD} / \%$ & Mean $/ n$ & $\mathrm{SD} / \%$ & Mean $/ n$ & $\mathrm{SD} / \%$ & Mean $/ n$ & $\mathrm{SD} / \%$ & & \\
\hline \multirow[t]{6}{*}{ Sociodemographic } & Age & 64.1 & 10.62 & 62.45 & 9.78 & 63.66 & 10.08 & 63.2 & 10.1 & 1.01 & \\
\hline & Sex (Male) & 71 & 65.1 & 150 & 85.2 & 65 & 73 & 286 & 76.5 & 15.87 & $* * *$ \\
\hline & $\begin{array}{l}\text { Ethnocultural background } \\
\text { (White) }\end{array}$ & 93 & 87.7 & 139 & 83.7 & 76 & 89.4 & 308 & 86.3 & 1.80 & \\
\hline & Marital status (Married) & 88 & 80.7 & 151 & 85.8 & 67 & 75.3 & 306 & 81.8 & 4.51 & \\
\hline & Work status (Full-time) & 43 & 39.8 & 78 & 44.3 & 76 & 40.4 & 157 & 42.1 & 0.69 & \\
\hline & $\begin{array}{l}\text { Family Income } \\
(>\$ 50,000 \mathrm{CAD} / \text { year })\end{array}$ & 44 & 48.4 & 102 & 70.3 & 41 & 54.7 & 187 & 60.1 & 12.51 & $*$ \\
\hline \multirow[t]{12}{*}{ Clinical } & Condition / Procedure (PCI) & 67 & 61.5 & 102 & 58 & 53 & 59.6 & 222 & 59.4 & 0.35 & \\
\hline & Obesity (BMI > 30, Yes) & 40 & 38.1 & 24 & 19.9 & 37 & 30.7 & $10 \mathrm{I}$ & 27.7 & 11.26 & $*$ \\
\hline & Diabetes (Yes) & 28 & 25.7 & 21 & 12 & 22 & 25 & 71 & 19.1 & 10.76 & $*$ \\
\hline & Arthritis (Yes) & 35 & 32.1 & 38 & 21.6 & 21 & 23.6 & 94 & 25.1 & 4.11 & \\
\hline & Previous exercise & & & & & & & & & & \\
\hline & Behavior (Yes) & 19 & 17.4 & 63 & 36.8 & 25 & 29.1 & 107 & 29.2 & 12.13 & $*$ \\
\hline & Smoker & & & & & & & & & 21.21 & $* * *$ \\
\hline & Current & 16 & 14.7 & 14 & 8 & 22 & 25.3 & 52 & 14 & & \\
\hline & Past & 66 & 60.6 & 88 & 50.3 & 38 & 43.7 & 192 & 51.8 & & \\
\hline & Never & 27 & 24.8 & 73 & 41.7 & 27 & 31 & 127 & 34.2 & & \\
\hline & CR attendance ${ }^{a}$ (Yes) & 23 & 21.1 & 94 & $\$ 3.4$ & 35 & 39.3 & 152 & 40.6 & 29.21 & *** \\
\hline & Functional status & 30.54 & 16.82 & 36.75 & 17.87 & 35.68 & 16.84 & 34.7 & 17.5 & 4.48 & * \\
\hline \multirow[t]{17}{*}{ Psychosocial } & Anxiety symptoms & 7.29 & 4.13 & 6.41 & 3.95 & 7.02 & 4.32 & 6.8 & 4.1 & 1.71 & \\
\hline & Depressive symptoms & 4.79 & 3.06 & 4.18 & 3.5 & 4.22 & 2.94 & 4.4 & 3.3 & 1.29 & \\
\hline & Physical quality of life & 36.79 & 10.75 & 40.09 & 10.8 & 39.07 & 10.41 & 38.9 & 10.8 & 2.94 & \\
\hline & Illness perceptions & & & & & & & & & & \\
\hline & Acute or chronic & 20.03 & 5.51 & 17.92 & 4.88 & 18.55 & 5.13 & 18.7 & 5.2 & 5.67 & $*$ \\
\hline & Cyclical or episodic & 11.05 & 3.26 & 10.65 & 3.3 & 10.89 & 3.25 & 10.8 & 3.3 & 0.50 & \\
\hline & CAD consequences & 19.74 & 4.38 & 19.68 & 4 & 19.98 & 4.75 & 19.8 & 4.3 & 0.14 & \\
\hline & Personal control & 24.59 & 3.1 & 24.15 & 4.21 & 24.42 & 3.62 & 24.3 & 3.8 & 0.48 & \\
\hline & Cure or controllability & 19.51 & 3.11 & 19.85 & 2.5 & 19.8 & 2.64 & 19.7 & 2.7 & 0.57 & \\
\hline & Cause-my own behavior & 3.69 & 0.99 & 3.26 & 1.2 & 3.7 & 0.93 & 3.5 & 1.1 & 7.47 & $* * *$ \\
\hline & Social support & & & & & & & & & & \\
\hline & Tangible support & 4.25 & 0.84 & 4.43 & 0.74 & 4.35 & 0.95 & 4.4 & 0.8 & 1.50 & \\
\hline & Affectionate support & 6.38 & 5.44 & 6.74 & 5 & 6.57 & 4.35 & 6.6 & 5 & 0.18 & \\
\hline & Positive social interaction & 4.24 & 0.86 & 4.39 & 0.69 & 4.34 & 0.84 & 4.3 & 0.8 & 1.18 & \\
\hline & Emotional /Informational & 4.26 & 0.83 & 4.38 & 0.74 & 4.34 & 0.86 & 4.3 & 0.8 & 0.83 & \\
\hline & Total & 4.78 & 1.68 & 4.98 & 1.52 & 4.89 & 1.5 & 4.9 & 1.6 & 0.52 & \\
\hline & Exercise barriers & 2.32 & 0.45 & 1.94 & 0.42 & 2.07 & 0.47 & 2.1 & 0.5 & 24.78 & $* * *$ \\
\hline \multirow{3}{*}{$\begin{array}{l}\text { Environmental- } \\
\text { survey completed } \\
\text { during winter } \\
\text { months }\end{array}$} & In-hospital survey (Yes) & 24 & 22 & 41 & 23.3 & 24 & 27 & 89 & 23.8 & 0.71 & \\
\hline & $\begin{array}{l}9 \text { months Post-discharge } \\
\text { (Yes) }\end{array}$ & 38 & 34.9 & 43 & 24.7 & 20 & 22.5 & 107 & 27.2 & 4.79 & \\
\hline & $\begin{array}{l}18 \text { months Post-discharge } \\
\text { (Yes) }\end{array}$ & 20 & 18.9 & 35 & 20.3 & 21 & 24.4 & 76 & 20.9 & 0.94 & \\
\hline
\end{tabular}

$*_{p}<0.05 ; * * * p<0.001$

a Assessed 9 months post-discharge, all others assessed in hospital unless indicated

$\mathrm{CAD}=$ coronary artery disease $\mathrm{CR}=$ Cardiac Rehabilitation 
Table 3 Multinomial logistic regression of correlates of Exercise Maintainers, Irregular Exercisers and Inactive Participants

\begin{tabular}{|c|c|c|c|}
\hline Group & Variables & OR & $95 \%$ Confidence Interval \\
\hline \multirow[t]{12}{*}{ Exercise Maintainers } & Exercise barriers & 0.183 & $(0.079-0.426)^{* * *}$ \\
\hline & Illness perceptions (acute vs. chronic) & 0.961 & $(0.900-1.026)$ \\
\hline & Functional status & 1.010 & $(0.990-1.030)$ \\
\hline & Illness perception: cause (my own behavior) & 0.505 & $(0.343-0.742)^{* * *}$ \\
\hline & Sex (male) & 4.060 & $(1.691-9.748)^{* *}$ \\
\hline & CR attendance (Yes) & 5.964 & $(2.865-12.416)^{* * *}$ \\
\hline & Family income $(>\$ 50,000 \mathrm{CAD} /$ year $)$ & 0.828 & $(0.418-1.638)$ \\
\hline & Diabetes (yes) & 0.448 & $(0.190-1.056)$ \\
\hline & Previous exercise behavior (Yes) & 3.054 & $(1.432-6.515)^{* *}$ \\
\hline & Current smoker & 0.209 & $(0.069-0.632)^{* *}$ \\
\hline & Past smoker & 0.349 & $(0.158-0.769)^{* *}$ \\
\hline & Obesity (BMI > 30 yes) & 0.909 & $(0.414-1.998)$ \\
\hline \multirow[t]{12}{*}{ Irregular Exercisers } & Exercise barriers & 0.217 & $(0.090-0.528)^{* *}$ \\
\hline & Illness perceptions (acute vs. chronic) & 0.979 & $(0.915-1.047)$ \\
\hline & Functional status & 1.013 & $(0.992-1.034)$ \\
\hline & Illness perception: cause (my own behavior) & 0.725 & $(0.484-1.085)$ \\
\hline & Sex (male) & 1.863 & $(0.811-4.282)$ \\
\hline & CR attendance (Yes) & 3.030 & $(1.413-6.497)^{* *}$ \\
\hline & Family income $(>\$ 50,000 \mathrm{CAD} /$ year $)$ & 1.240 & $(0.611-2.517)$ \\
\hline & Diabetes (yes) & 1.088 & $(0.484-2.445)$ \\
\hline & Previous exercise behavior (Yes) & $1.90 \mathrm{I}$ & $(0.854-4.234)$ \\
\hline & Current smoker & 0.908 & $(0.330-2.498)$ \\
\hline & Past smoker & 0.479 & $(0.207-1.108)$ \\
\hline & Obesity (BMI > 30 yes) & 1.074 & $(0.486-2.374)$ \\
\hline
\end{tabular}

Reference group: Inactive participants; OR, Odds Ratio; $\mathrm{CR}$, Cardiac rehabilitation

${ }^{* *} p<0.01, * * * p<0.001$

Table 4 Logistic regression of correlates of Irregular Exercisers vs. Exercise Maintainers

\begin{tabular}{llll}
\hline Group & Variables & OR & 95\% Confidence Interval \\
\hline Irregular exercisers & Exercise barriers & 1.039 & $(0.467-2.308)$ \\
& Illness perceptions (acute vs. chronic) & 1.033 & $(0.968-1.102)$ \\
& Functional status & 1.003 & $(0.984-1.023)$ \\
& Ilness perception: cause (my own behavior) & 1.455 & $(1.045-2.026)^{*}$ \\
& Sex (male) & 0.469 & $(0.195-1.124)$ \\
& CR attendance (Yes) & 0.534 & $(0.280-1.017)$ \\
& Family income (>\$50,000CAD/year) & 1.410 & $(0.716-2.779)$ \\
& Diabetes (yes) & 2.497 & $(1.083-5.759)^{*}$ \\
& Previous exercise behavior (Yes) & 0.671 & $(0.341-1.319)$ \\
& Current smoker & 3.906 & $(1.413-10.795)^{* *}$ \\
& Past smoker & 1.257 & $(0.612-2.582)$ \\
& Obesity (BMI > 30 yes) & 1.313 & $(0.616-2.797)$ \\
\hline
\end{tabular}

Reference group: Exercise maintainers

$\mathrm{OR}$, Odds Ratio; CR, Cardiac rehabilitation

${ }^{*} p<0.05 ; * * p<0.01$ 
Sociodemographic and Clinical Correlates of Exercise Patterns

This research identified significant sociodemographic and clinical correlates related to exercise maintenance in cardiac populations such as sex, exercise history, diabetes, smoking, and cardiac rehabilitation participation which are consistent with previous research (Grace et al. 2007a; Moore et al. 2003; Reid et al. 2006; Song and Lee 2001). It was notable that we found no differences in exercise patterns based on age, family income or ethnocultural background in controlled analyses, given older, low socioeconomic status and non-white populations are often most vulnerable to inactivity and CAD (Daly et al. 2002; Taylor et al. 1998). Perhaps these sociodemographic characteristics are more relevant to exercise initiation rather than maintenance.

Sex was only a significant correlate in the model distinguishing between Exercise Maintainers and Inactive participants. Thus, this study replicated the greater physical activity among men than women seen in cardiac rehabilitation populations (Lieberman et al. 1998), but further suggests men may also be more likely to sustain this activity. While there is greater awareness of women's inactivity and the subsequent increased risk for cardiac recurrence, clearly more efforts to increase and sustain women's activity levels are critically needed.

The goals of cardiac rehabilitation are to promote secondary prevention and increase quality of life by providing exercise training, risk factor modification, education, medical surveillance, vocational rehabilitation and psychosocial counseling (McGee et al. 1999; World Health Organization 1993). Empirical evidence shows that completion of cardiac rehabilitation programs is related to increased exercise tolerance (Balady et al. 1996; Milani et al. 2004), exercise maintenance, quality of life, and leisure-time physical activity (Izawa et al. 2004), as well as improved perception of physical function (Dolansky and Moore 2004). Given the quantity of evidence supporting the effects of cardiac rehabilitation in increasing physical activity and overcoming psychosocial barriers to exercise (Boesch et al. 2005; Lavie and Milani 1996; Lavie et al. 1999; Song and Lee 2001; Worcester et al. 2003), it was not surprising that cardiac rehabilitation enrollment distinguished significantly among Irregular Exercisers and Inactive participants, and between Exercise Maintainers and Inactive participants. Given the gross under-utilization of cardiac rehabilitation in many jurisdictions (Bittner et al. 1999; Bunker and Goble 2003; Grace et al. 2002), continued efforts to increase enrollment such as automatic referral are warranted (Grace et al. 2004).

Confirming (Blanchard et al. 2002; Bozionelos and Bennett 1999; Brenes et al. 1998) and extending previous findings, participants who had a previous exercise history were less likely to be Inactive 18 months later when compared to both Exercise Maintainers and Irregular Exercisers. This emphasizes the importance of lifelong physical activity promotion to increase the likelihood exercise will become a lifestyle habit, particularly given exercise may protect against other cardiac risk factors including smoking (Blair et al. 1996).

\section{Psychosocial and Environmental Correlates of Exercise Patterns}

Exercise barriers and causal attributions were found to play an important role in exercise maintenance behavior (McAuley 1993). Perceived exercise barriers, including personal (e.g., motivation, fatigue, time), social (e.g., partner support), and environmental (e.g., cost, access, weather) barriers (Evenson and Fleury 2000; Trost et al. 2002; Wyer et al. 2001) appear to be a consistent and strong influence on exercise (Carlson et al. 2000; Trost et al. 2002). It is important to identify and understand potential barriers thereby enabling effective solutionplanning before barriers arise. For example, if a specific barrier such as lack of access to facilities is identified among older populations, a cardiac rehabilitation referral could be made or a list of potential venues could be generated in collaboration with the patient (Karner et al. 2005; Roitman and LaFontaine 2001; Taylor et al. 1998).

Inactive Participants were more likely to attribute their CAD to their own behavior than Exercise Maintainers, as were Irregular Exercisers when compared to Exercise Maintainers. Perhaps Inactive and Irregular participants were aware that their sedentary lifestyle is detrimental to their cardiac health, however this knowledge is insufficient to motivate them to initiate and maintain physical activity. Considering awareness of the need to change is often the first step towards adopting exercise (Prochaska and DiClemente 2005), subsequent interventions can capitalize on this to move cardiac patients towards action. Future study examining how this cardiac casual attribution relates to exercise initiation is warranted.

Finally, while the season of assessment was not a significant correlate of exercise, future research is needed to thoroughly examine other environmental characteristics such as sidewalk access, fear of falling, and temperature considering these have been identified as important influences on physical activity participation in older adults (Trost et al. 2002).

Caution is warranted when interpreting these results, due mainly to measurement and generalizability issues. First, the reliance on self-report assessment of exercise behavior raises the potential of inaccuracy in reporting. For instance, research shows that sedentary adults are more likely to 
overestimate their exertion level than their more active counterparts (Duncan et al. 2001). Self-report assessment is however common in exercise behavior research, and the HPLP II is a valid and reliable instrument (Walker et al. 1987). Moreover, our operationalization of exercise patterns through the use of median split at all three time points has several limitations. For instance, it reduces the variability in scores, or may misclassify some participants as inactive even if they had increased the exercise behavior across time. Future research utilizing growth curve modeling of exercise behavior over time is warranted. Second, selection biases such as significant differences in characteristics of participants and non-participants, and the fact that the retained participants were more likely to exercise than those lost to follow-up limit generalizability of the findings. Third, the list of correlates examined in this study although thorough, was not exhaustive. Finally, given the nature of our study design, causal conclusions cannot be drawn.

In conclusion, this study revealed that up to one-fifth of cardiac patients may have difficulty maintaining exercise following initiation. Identified correlates of exercise maintenance following a coronary event or procedure were male gender, attending cardiac rehabilitation, prior exercise history, being a non-smoker, perceiving lower exercise barriers, and being less likely to attribute their disease to their own behavior. Future research is needed to investigate the rate of Irregular Exercisers among cardiac patients to see whether this high rate is replicated, and if so to explore means to promote sustained activity.

Acknowledgements This research was funded by Canadian Health Services Research Foundation (CHSRF) and Ontario Ministry of Health and Long-term Care (OMHLTC), and administered by the Canadian Institutes of Health Research. Ms. Leung is supported by GENESIS Gender and Sex Determinants of Circulatory and Respiratory Diseases: Interdisciplinary Enhancement Teams Grant Program, Canadian Institutes of Health Research and the Heart and Stroke Foundation of Canada, and Dr. Grace is supported by the OMHLTC. Special thanks to Suzan Krepostman and Laura Ewart for recruitment activities.

\section{References}

Balady, G. J., Jette, D., Scheer, J., \& Downing, J. (1996). Changes in exercise capacity following cardiac rehabilitation in patients stratified according to age and gender. Results of the Massachusetts association of cardiovascular and pulmonary rehabilitation multicenter database. Journal of Cardiopulmonary Rehabilitation, 16, 38-46.

Bittner, V., Sanderson, B., Breland, J., \& Green, D. (1999). Referral patterns to a university-based cardiac rehabilitation program. The American Journal of Cardiology, 83, 252-5, A5.

Bjelland, I., Dahl, A. A., Haug, T. T., \& Neckelmann, D. (2002). The validity of the hospital anxiety and depression scale. An updated literature review. Journal of Psychosomatic Research, 52, 69-77.
Blair, S. N., Kampert, J. B., Kohl, H. W., Barlow, C. E., Macera, C. A., \& Paffenbarger, R. S. Jr. (1996). Influences of cardiorespiratory fitness and other precursors on cardiovascular disease and all-cause mortality in men and women. Journal of the American Medical Association, 276, 1-12.

Blanchard, C. M., Courneya, K. S., Rodgers, W. M., Daub, G., \& Knapik, G. (2002). Determinants of exercise intention and behaviour during and after phase 2 cardiac rehabilitation: An application of the theory of planned behaviour. Rehabilitation Psychology, 47, 308-323.

Boesch, C., Myers, J., Habersaat, A., Marraza, H., Kottman, W., \& Dubach, P. (2005). Maintenance of exercise capacity and physical activity patterns 2 years after cardiac rehabilitation. Journal of Cardiopulmonary Rehabilitation, 25, 14-21; quiz 22-3.

Borg, G. A. (1974). Perceived exertion, Exercise and Sport Sciences Reviews, 2, 131-153.

Bozionelos, G., \& Bennett, P. (1999). The theory of planned behaviour as predictor of exercise: The moderating influence of beliefs and personality variables, Journal of Health Psychology, 4, 517-529.

Brawley, L. R., Rejeski, W. J., \& King, A. C. (2003). Promoting physical activity for older adults: The challenges for changing behavior. American Journal of Preventive Medicine, 25(3 Suppl 2), SI72-S183.

Brenes, G. A., Strube, M. J., \& Storandt, M. (1998). An application of the theory of planned behavior to exercise among older adults. Journal of Applied Social Psychology, 25(3sii), 172-183.

Bunker, S. J., \& Goble, A. J. (2003). Cardiac rehabilitation: Underreferral and underutilisation. The Medical Journal of Australia, 179, 332-333.

Carlson, J. J, Johnson, J. A., Franklin, B. A., \& VanderLaan, R. L. (2000). Program participation, exercise adherence, cardiovascular outcomes, and program cost of traditional versus modified cardiac rehabilitation. American Journal of Cardiology, 86, 17-23.

Chan, S. Y., Mancini, J., Burns, S., Johnson, F. F., Brozic, A. P., \& Kingsbury, K. (2006b). Dietary measures and exercise training contribute to improvement of endothelial function and atherosclerosis even in patients given intensive pharmacologic therapy. Journal of Cardiopulmonary Rehabilitation, 26, 288-293.

Chan, C. B., Ryan, D. A., \& Tudor-Locke, C. (2006a). Relationship between objective measures of physical activity and weather: A longitudinal study. The International Journal of Behavioral Nutrition and Physical Activity, 3, 21.

Daly, J., Sindone, A. P., Thompson, D. R., Hancock, K., Chang, E., \& Davidson, P. (2002). Barriers to participation in and adherence to cardiac rehabilitation programs: A critical literature review. Progress in Cardiovascular Nursing, 17, 8-17.

Dillman, D. A. (2000). Mail and internet surveys: The tailored design method (2nd ed.). New York: John Wiley \& Sons, Inc.

Dolansky, M. A., \& Moore, S. M. (2004). Effects of cardiac rehabilitation on the recovery outcomes of older adults after coronary artery bypass surgery. Journal of Cardiopulmonary Rehabilitation, 24, 236-244.

Duncan, G. E., Sydeman, S. J., Perri, M. G., Limacher, M. C., \& Martin, A. D. (2001). Can sedentary adults accurately recall the intensity of their physical activity? Preventive Medicine, 33 $18-26$.

Evenson, K. R., \& Fleury, J. (2000). Barriers to outpatient cardiac rehabilitation participation and adherence. Journal of Cardiopulmonary Rehabilitation, 20, 241-246.

Gielen, S., \& Hambrecht, R. (2001). Effects of exercise training on vascular function and myocardial perfusion. Cardiology Clinics, 19, 357-368. 
Grace, S. L., Abbey, S. E., Shnek, Z. M., Irvine, J., Franche, R. L., \& Stewart, D. E. (2002). Cardiac rehabilitation II: Referral and participation. General Hospital Psychiatry, 24, 127-134.

Grace, S. L., Barry-Bianchi, S., Stewart, D. E., Rukholm, E., \& Nolan, R. P. (2007a). Physical activity behaviour, motivational readiness and self-efficacy among Ontarians with cardiovascular disease and diabetes. Journal of Behavioral Medicine, 30(1), 21-29.

Grace, S. L., Evindar, A., Kung, T. N., Scholey, P. E., \& Stewart, D. E. (2004), Automatic referral to cardiac rehabilitation. Medical Care, 42, 661-669.

Grace, S. L., Leung, Y. W., \& Stewart, D. E. (In press). A prospective examination of antidepressant use and its correlates in acute coronary syndrome patients. Psychosomatics.

Grace, S. L., Scholey, P., Suskin, N., Arthur, H., Brooks, D., \& Jaglal, S. (2007b). A prospective comparison of cardiac rehabilitation enrolment following automatic versus usual referral. Journal of Rehabilitation Medicine, 39, 239-245.

Hambrecht, R., Niebauer, J., Marburger, C., Schoppenthau, M., Kalberer, B., \& Shlierf, B. (I993). Various intensities of leisure time physical activity in patients with coronary artery disease: Effects on cardiorespiratory fitness and progression of coronary artherosclerotic lesions. Journal of the American College of Cardiology, 22, 468-477.

Hatky, M. A., Boineau, R. E., Higginbotham, M. B., Lee, K. L., Mark, D. B., \& Califf, R. M. (1989). A brief self-administered questionnaire to determine functional capacity (the duke activity status index). The American Journal of Cardiology, 64, 651-654.

Izawa, K. P., Yamada, S., Oka, K., Watanabe, S., Omiya, K., Iijima, $S$. et al. (2004). Long-term exercise maintenance, physical activity, and health-related quality of life after cardiac rehabilitation. American Journal of Physical Medicine \& Rehabilitation/Association of Academic Physiatrists, 83, 884-892.

Jassen, I., \& Jolliffe, C. J. (2006). Influence of physical activity on mortality in elderly with coronary artery disease. Medicine and Science in Sports and Exercise, 38, 417-418.

Karner, A., Tingstrom, P., Abrandt-Dahlgren, M., \& Bergdahl, B. (2005). Incentives for lifestyle changes in patients with coronary heart disease. Journal of Advanced Nursing, 51, 261-275.

Lavie, C. J., \& Milani, R. V. (1996). Effects of cardiac rehabilitation and exercise training programs in patients $>$ or $=75$ years of age. The American Journal of Cardiology, 78, 675-677.

Lavie, C. J., Milani, R. V., Cassidy, M. M., \& Gilliland, Y. E. (1999). Effects of cardiac rehabilitation and exercise training programs in women with depression. The American Journal of Cardiology, $83,1480-1483$, A7.

Leon, A. S., Franklin, B. A., Costa, F., Balady, G. J., Berra, K. A., \& Stewart, K. J. (2005). Cardiac rehabilitation and secondary prevention of coronary heart disease. Circulation, 111, 369-376.

Lieberman, L., Meana, M., \& Stewart, D. (1998). Cardiac rehabilitation: Gender differences in factors influencing participation. Journal of Women's Health, 7, 717-723.

Manuel, D. G., Leung, M., Nguyen, K., Tanuseputro, P., \& Johansen, H. (2006). Burden of cardiovascular disease in Canada. In J. V. Tu, W. A. Ghali, L. Pilote, \& S. Brien (Eds.), CCORT. Canadian Cardiovascular Atlas (pp. 15-22). Canada: Pulsus Group Inc and Institute for Clinical Evaluative Sciences.

McAuley, E. (1993). Self-efficacy and the maintenance of exercise participation in older adults. Journal of Behavioral Medicine, 16, 103-113.

McGee, H. M., Hevey, D., \& Horgan, J. H. (1999), Psychosocial outcome assessments for use in cardiac rehabilitation service evaluation: A 10-year systematic review. Social Science \& Medicine, 48, 1373-1393.

Milani, R. V., Lavie, C. J., \& Mehra, M. R. (2004). Reduction in $\mathrm{C}$-reactive protein through cardiac rehabilitation and exercise training. Journal of the American College of Cardiology, 43 1056-1061.

Moore, S. M., Dolansky, M. A., Ruland, C. M., Pashkow, F. J., \& Blackburn, G. G. (2003). Predictors of women's exercise maintenance after cardiac rehabilitation. Journal of Cardiopulmonary Rehabilitation, 23, 40-49.

Moss-Morris, R., Weinman, J., Petrie, K. J., Home, R., Cameron, L. D., \& Buick, D. (2002). The revised illness perception questionnaire (IPQ-R). Psychology \& Health, 17, 1-16.

Nelson, C. L., Herndon, J. E., Mark, D. B., Pryor, D. B., Califf, R. M., \& Hlatky, M. A. (1991). Relation of clinical and angiographic factors to functional capacity as measured by the duke activity status index. The American Journal of Cardiology, 68, 973-975.

Niebauer, J., Hambrecht, R., Velich, T., Hauer, K., Marburger, C., \& Kalberer, B. (1997). Attenuated progression of coronary artery disease after 6 years of multifactorial risk intervention. Circulation, 96, 2534-2541.

O'Clark, D. (1999). Physical activity and its correlates among urban primary care patients aged 55 years or older. The Journals of Gerontology, 54B, S41-S49.

Prochaska, J. O., \& DiClemente, C. C. (2005). The transtheoretical approach. New York, NY, USA: Oxford University Press.

Reid, R. D., Morrin, L. I., Pipe, A. L., Dafoe, W. A., Higginson, L. A., Wielgosz, A. T., McDonald, P. W., Plotnikoff, R. C., Courneya, K. S., Oldridge, N. B., Beaton, L. J., Papadakis, S., Slovinec D'Angelo, M. E., Tulloch, H. E., \& Blanchard, C. M. (2006). Determinants of physical activity after hospitalization for coronary artery disease: The tracking exercise after cardiac hospitalization (TEACH) study. European Journal of Cardiovascular Prevention and Rehabilitation: Official Journal of the European Society of Cardiology, Working Groups on Epidemiology \& Journal of Cardiovascular Prevention and Cardiac Rehabilitation and Exercise Physiology, 13, 529-537.

Roitman, J., \& LaFontaine, T. (2001). Modified protocols for cardiovascular rehabilitation and program efficacy. Journal of Cardiopulmonary Rehabilitation, 21, 374-376.

Sechrist, K. R., Walker, S. N., \& Pender, N. J. (1987). Development and psychometric evaluation of the exercise benefits/barriers scale. Research in Nursing \& Health, 10, 357-365.

Sherbourne, C. D., \& Stewart, A. L. (1991). The MOS social support survey. Social Science \& Medicine, 32, 705-714.

Song, R., \& Lee, H. (2001). Effects of a 12-week cardiac rehabilitation exercise program on motivation and health-promoting lifestyle. Heart \& Lung: The Journal of Acute and Critical Care $30,200-209$.

Taylor, W. C., Baranowski, T., \& Rohm Young, D. (1998). Physical activity interventions in low-income, ethnic minority, and populations with disability. American Joumal of Preventive Medicine, 15, 334-343.

Trost, S. G., Owen, N., Bauman, A. E., Sallis, J. F., \& Brown, W. (2002). Correlates of adults' participation in physical activity: Review and update. Medicine and Science in Sports and Exercise, 34, 1996-2001.

Walker, S. N., Sechrist, K. R., \& Pender, N. J. (1987). The healthpromoting lifestyle profile: Development and psychometric characteristics. Nursing Research, 36, 76-81

Wilcox, S., \& Storandt, M. (1996). Relations among age, exercise, and psychological variables in a community sample of women. Health Psychology: Official Journal of the Division of Health Psychology, American Psychological Association, 15, 110-113.

Worcester, M. U., Stojcevski, Z., Murphy, B., \& Goble, A. J. (2003). Long-term behavioral outcomes after attendance at a secondary prevention clinic for cardiac patients. Journal of Cardiopulmonary Rehabilitation, 23, 415-422.

World Health Organization. (1993). Needs and action priorities in cardiac rehabilitation and secondary prevention in patients with 
coronary heart disease. Geneva, Switzerland: WHO Regional Office for Europe.

World Health Organization. (2006). Obesity and overweight. What are obesity and overweight? Retrieved April, 2007, from http:/I www.who.int/mediacentre/factsheets/fs $311 / \mathrm{en} /$
Wyer, S., Joseph, S., \& Earll, L. (2001). Predicting attendance at cardiac rehabilitation: A review and recommendations. Coronary Health Care, 5, 171-177.

Zigmond, A. S., \& Snaith, R. P. (1983). The hospital anxiety and depression scale. Acta Psychiatrica Scandinavica, 67, 361-370. 